Check for updates

Cite this: RSC Adv., 2018, 8, 22986

Received 4th April 2018

Accepted 17th June 2018

DOI: 10.1039/c8ra02901f

rsc.li/rsc-advances

\section{A novel binary flooding system of a biobased surfactant and hydrophobically associating polymer with ultralow interfacial tensions $\dagger$}

\author{
$\mathrm{Na}$ Li, (D) ${ }^{a}$ Xin-Ning Bao, ${ }^{\text {ab }}$ Yong-Jun Guo, ${ }^{\mathrm{C}}$ Shi-Zhong Yang, ${ }^{\mathrm{a}}$ Ying-Cheng Li ${ }^{\star b}$ \\ and Bo-Zhong Mu iD *a
}

The alkali free surfactant-polymer flooding system with ultralow interfacial tension is a challenge in enhanced oil recovery at present. A novel alkali free binary flooding system of a biobased zwitterionic surfactant and hydrophobically associating polymer with ultralow interfacial tension at a low surfactant dosage was studied in this paper.
Ternary alkali-surfactant-polymer (ASP) flooding, as one of the representative chemical methods, has been successfully applied in enhanced oil recovery (EOR) in last few decades. ${ }^{1-4}$ However, the alkali in the ASP system simultaneously resulted in the reduction of reservoir permeability due to the dispersion and migration of clay and the alkaline scaling in formation. ${ }^{5}$ Alkalifree binary surfactant-polymer (SP) flooding with ultralow interfacial tension $\left(\leq 10^{-3} \mathrm{mN} \mathrm{m}^{-1}\right)$ is a promising approach among tertiary oil recovery methods. It has received much attention from both the scientific and industrial communities since two-thirds of crude oil were still trapped in oil reservoirs after primary and secondary oil recovery. ${ }^{1,6}$ Over the past few years, SP flooding has been conducted on modest scales and significantly improved EOR efficiency in Daqing Oilfield ${ }^{7}$ and Shengli Oilfield, ${ }^{8}$ China. In the absence of alkali, however, the most traditional surfactant-polymer flooding systems could not reach the required ultralow interfacial tension, and may consequently fail in EOR. ${ }^{2,9,10}$

In the present work, we developed an alkali free binary flooding system consisting of the biobased zwitterionic surfactant and hydrophobically associating polymer with ultralow interfacial tension. Zwitterionic surfactants usually have lower critical micelle concentration (CMC) ${ }_{1}^{11}$ better water solubility ${ }^{12}$ and satisfied interfacial tensions. ${ }^{13}$ The biobased zwitterionic surfactant ( $N$-phenyloctade-canoicamidopropyl- $N, N$-dimethylcarboxylbetaine, POAPMB) synthesized using renewable

${ }^{a}$ State Key Laboratory of Bioreactor Engineering, School of Chemistry and Molecular Engineering, East China University of Science and Technology, Shanghai 200237, P. R. China. E-mail: bzmu@ecust.edu.cn; Fax: +86 21 64252485; Tel: +86 2164252063 ${ }^{b}$ Sinopec Key Lab of Surfactants for EOR, Sinopec Shanghai Research Institute of Petrochemical Technology, Shanghai 201208, P. R. China. E-mail: liyc.sshy@ sinopec.com

'State Key Laboratory of Oil and Gas Reservoir Geology and Exploitation, Southwest Petroleum University, Chengdu 610500, P. R. China

$\dagger$ Electronic supplementary information (ESI) available. See DOI: $10.1039 / \mathrm{c} 8 \mathrm{ra0} 2901 \mathrm{f}$ feedstock in our laboratory demonstrated excellent surface/ interfacial activity and environmental biodegradability, and its CMC was $5.58 \times 10^{-6} \mathrm{~mol} \mathrm{~L}^{-1} \cdot{ }^{14}$ The hydrophobically associating polymer (AP-P3) was synthesized in the laboratory as described in published literature. ${ }^{5}$ The structures of POAPMB and hydrophobically associating polymer were illustrated in Fig. 1. The interfacial tension (IFT), viscosity and phase behavior of the biobased zwitterionic surfactant/ hydrophobically associating polymer binary system were investigated, which is, to the best of our knowledge, the first report about the SP flooding of alkali free biobased zwitterionic surfactant and hydrophobically associating polymer flooding system.

Unless otherwise specified, the POAPMB/AP-P3 system configured by Daqing simulated formation water (downhole temperature $\left.45^{\circ} \mathrm{C}\right)$ consisted of $0.50 \mathrm{~g} \mathrm{~L}^{-1}$ POAPMB $(\sim 0.95 \mathrm{mM})$ and $1.50 \mathrm{~g} \mathrm{~L}^{-1} \mathrm{AP}-\mathrm{P} 3$ in the experiment. The interfacial tensions were measured by a spinning drop interfacial tensiometer at $45^{\circ} \mathrm{C}$. The IFT between simulated formation water and Daqing crude oil (the acid value: $0.06 \mathrm{mg} \mathrm{KOH} \mathrm{per} \mathrm{g)} \mathrm{was} 9.9 \mathrm{mN} \mathrm{m}^{-1}$ at $45{ }^{\circ} \mathrm{C}$. The viscosity of POAPMB/AP-P3 system was measured by a rheometer at $45^{\circ} \mathrm{C}$.

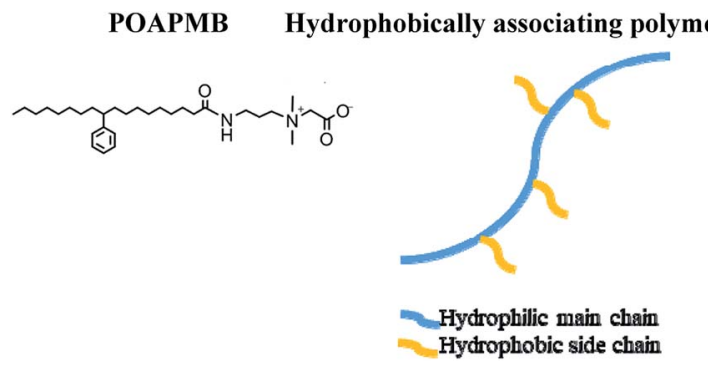

Fig. 1 Structures of POAPMB and hydrophobically associating polymer. 

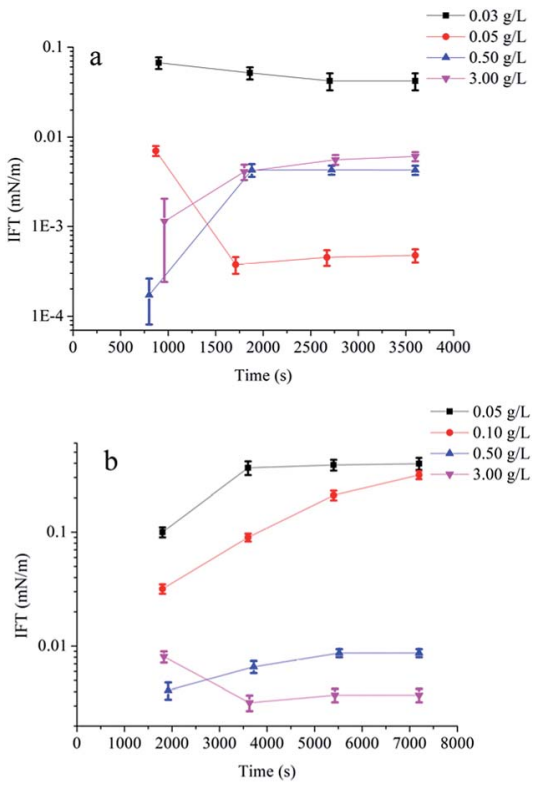

Fig. 2 The IFT between crude oil and different concentrations of POAPMB solutions (a) and in the presence of $1.50 \mathrm{~g} \mathrm{~L}^{-1}$ AP-P3 (b) $(n=3)$.

Dynamic interfacial tensions between Daqing crude oil and different concentrations of surfactant solutions alone and in the presence of $1.50 \mathrm{~g} \mathrm{~L}^{-1}$ AP-P3 were showed in Fig. 2a and b (ESI Fig. 1a and $\mathrm{b} \dagger$ ). The ultralow IFT could be achieved at a concentration as low as $0.05 \mathrm{~g} \mathrm{~L}^{-1}$ (Fig. 2a and ESI Fig. 1a†), which is fifty times lower than that of the sugar-based anionicnonionic surfactant ${ }^{15}$ (ESI Table $11 \dagger$ ). Most of alkylbenzene sulfonates ${ }^{\mathbf{1 6}}$ and propyl sulfobetaine $\mathrm{e}^{\mathbf{1 7}}$ can not achieve ultralow IFT without alkali.

For the binary system POAPMB/AP-P3 $\left(1.50 \mathrm{~g} \mathrm{~L}^{-1}\right)$ solution, the ultralow IFT was reached when the POAPMB concentrations ranged from $0.50 \mathrm{~g} \mathrm{~L}^{-1}$ to $3.00 \mathrm{~g} \mathrm{~L}^{-1}$ (Fig. $2 \mathrm{~b}$ and ESI Fig. $1 \mathrm{~b} \dagger$ ), which implies that the POAPMB/AP-P3 system is promisingly applicable in tertiary oil recovery. The addition of the polymer increased minimum transient IFT ( IFT $_{\text {min }}$ ), and it is possibly due to the formation of mixed micelle-like associations on the interface led to decline of interfacial free surfactant molecules and the lose adsorption. ${ }^{6,9}$ In addition, it took more time to achieve the balance of IFT in the presence of the polymer. Compared with nonionic surfactant ${ }^{\mathbf{1 0}}$ (ESI Table $11 \dagger$ ), POAPMB/ AP-P3 binary system can effectively reduce interfacial tensions.
In addition to the ultralow IFT, the performances of antidilution, stability, adsorption resistance, temperature adaptability, and salt tolerance also play an important role in SP flooding technology. For the anti-dilution, POAPMB/AP-P3 system achieved ultralow IFT when the solution was diluted to one eighth (Table 1). In this case, the viscosity retention rate was $8 \%$ (ESI Table $4 \dagger$ ). For $3.00 \mathrm{~g} \mathrm{~L}^{-1}$ POAPMB solution with $1.50 \mathrm{~g}$ $\mathrm{L}^{-1}$ AP-P3, ultralow IFT could be achieved even if it was diluted to one fortieth (ESI Table $2 \dagger$ ).

Table 2 showed that the IFT $_{\min }$ and equilibrium interfacial tension ( IFT $_{\text {equ }}$ ) of the binary system after aging. It could be seen that the IFT $_{\min }$ was below $0.01 \mathrm{mN} \mathrm{m}^{-1}$ after aging for 100 days. The POAPMB/AP-P3 system stability of ultralow IFT $_{\text {equ }}$ can last for 60 days. It was reported Gemini-non-ionic mixed surfactant and polymer stability of ultralow IFT can last for 90 days $^{5}$ (ESI Table $11 \dagger$ ).

The binary system and Daqing oil sands were mixed at the weight fraction ratio of $9 / 1$. The mixture was shook at $45^{\circ} \mathrm{C}$ for $24 \mathrm{~h}$ by shaking water bath. The IFT between Daqing crude oil and the supernatants was then measured. If the value of IFT was below $0.01 \mathrm{mN} \mathrm{m}^{-1}$, fresh sands were added to the remaining supernatants at the same weight fraction. Repeat the above operation until the IFT of the solution was above $0.01 \mathrm{mN} \mathrm{m}^{-1}$. The total number of times that an ultralow IFT achieved were taken as the measurement for evaluating the resistance of a surfactant formulation against adsorption by sandstone. ${ }^{2}$ For the binary system, ultralow IFT was achieved after two cycles (Table 3). At this time, the viscosity retention rate of the binary system was $93 \%$ (ESI Table $5 \dagger$ ). Ultralow IFT was achieved after three cycles for the solution of $3.00 \mathrm{~g} \mathrm{~L}^{-1}$ (about $5.71 \mathrm{mM}$ ) POAPMB with $1.50 \mathrm{~g} \mathrm{~L}^{-1}$ AP-P3 (ESI Table $3 \dagger$ ). It is recognized that the Daqing oil sands are negatively charged. Due to electrostatic attraction, hydrogen bonding, ion-exchange, chainchain interaction, covalent bonding, and hydrophobic bonding, as well as solvation of various species, ${ }^{\mathbf{1 8 , 1 9}}$ the saturated adsorption of different types of surfactants followed an order of anionic $<$ nonionic $<$ zwitterionic $<$ cationic surfactants. ${ }^{2,9,10,20}$ Yan et $a .^{2}$ reported that a nonionic/zwitterionic formulation with polyacrylamide achieved four times the ultralow IFT (ESI Table $11 \dagger$ ).

Fig. 3 showed IFTs of POAPMB/AP-P3 system at different temperatures. The IFT $_{\text {min }}$ of POAPMB/AP-P3 system was below $0.01 \mathrm{mN} \mathrm{m}^{-1}$ at $50{ }^{\circ} \mathrm{C}$ to $90{ }^{\circ} \mathrm{C}$ (Fig. 3 and ESI Fig. $2 \dagger$ ). But the

Table 1 The minimum IFTs and the equilibrium IFTs between crude oil and POAPMB/AP-P3 system diluted $(n=3)$

\begin{tabular}{|c|c|c|}
\hline Dilution multiple & $\begin{array}{l}0.5 \mathrm{~g} \mathrm{~L}^{-1} \text { POAPMB }+1.5 \mathrm{~g} \mathrm{~L}^{-1} \\
\text { AP-P3 } \operatorname{IFT}_{\min }\left(\mathrm{mN} \mathrm{m}^{-1}\right)\end{array}$ & $\begin{array}{l}0.5 \mathrm{~g} \mathrm{~L}^{-1} \text { POAPMB }+1.5 \mathrm{~g} \mathrm{~L}^{-1} \\
\text { AP-P3 } \operatorname{IFT}_{\text {equ }}\left(\mathrm{mN} \mathrm{m}^{-1}\right)\end{array}$ \\
\hline 1 & $(4.1 \pm 0.3) \times 10^{-3}$ & $(8.7 \pm 0.3) \times 10^{-3}$ \\
\hline 3 & $(6.4 \pm 0.5) \times 10^{-4}$ & $(1.5 \pm 0.1) \times 10^{-3}$ \\
\hline 4 & $(1.6 \pm 0.3) \times 10^{-4}$ & $(2.6 \pm 0.2) \times 10^{-3}$ \\
\hline 5 & $(2.9 \pm 0.2) \times 10^{-5}$ & $(4.1 \pm 0.3) \times 10^{-3}$ \\
\hline 8 & $(2.4 \pm 0.3) \times 10^{-4}$ & $(2.4 \pm 0.3) \times 10^{-4}$ \\
\hline 9 & $(5.1 \pm 0.3) \times 10^{-1}$ & $(9.9 \pm 0.4) \times 10^{-1}$ \\
\hline
\end{tabular}


Table 2 The $\mathrm{IFT}_{\text {min }}$ and IFT equ between crude oil and POAPMB/AP-P3 system with aging time $\left(45^{\circ} \mathrm{C}, n=3\right)$

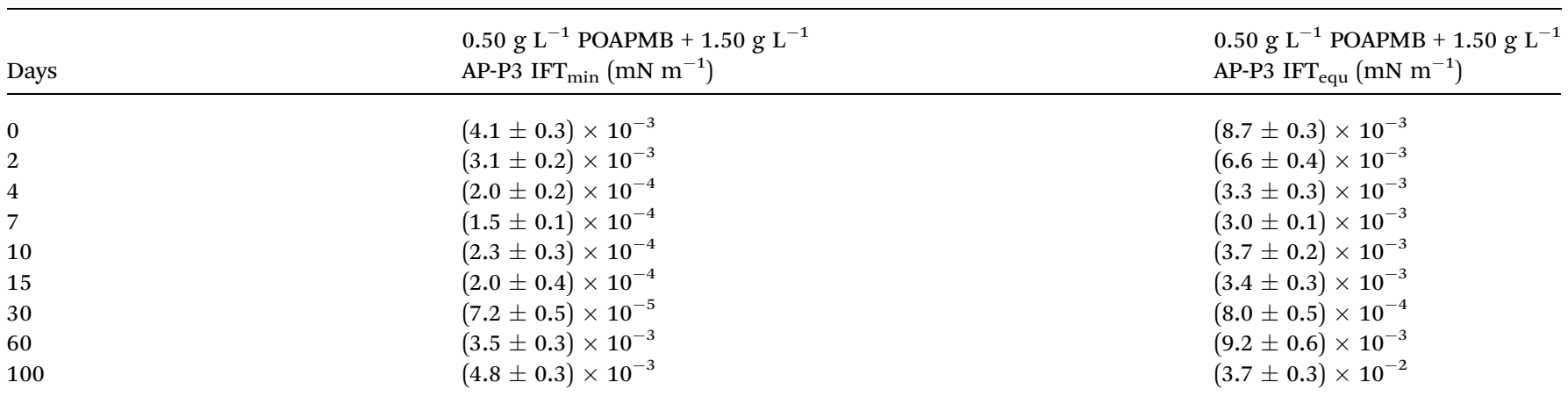

Table 3 The $\mathrm{IFT}_{\text {min }}$ and $\mathrm{IFT}_{\text {equ }}$ between crude oil and POAPMB/AP-P3 system after adsorption $\left(45^{\circ} \mathrm{C}, n=3\right)$

\begin{tabular}{|c|c|c|}
\hline Times & $\begin{array}{l}0.5 \mathrm{~g} \mathrm{~L}^{-1} \text { POAPMB }+1.5 \mathrm{~g} \mathrm{~L}^{-1} \\
\text { AP-P3 } \mathrm{IFT}_{\min }\left(\mathrm{mN} \mathrm{m}^{-1}\right)\end{array}$ & $\begin{array}{l}0.5 \mathrm{~g} \mathrm{~L}^{-1} \text { POAPMB }+1.5 \mathrm{~g} \mathrm{~L}^{-1} \\
\text { AP-P3 } \mathrm{IFT}_{\text {equ }}\left(\mathrm{mN} \mathrm{m}^{-1}\right)\end{array}$ \\
\hline 1 & $(4.4 \pm 0.4) \times 10^{-4}$ & $(4.4 \pm 0.3) \times 10^{-4}$ \\
\hline 3 & $(8.8 \pm 0.4) \times 10^{-1}$ & $(9.7 \pm 0.2) \times 10^{-1}$ \\
\hline
\end{tabular}

IFT $_{\text {equ }}$ showed an upward trend and roughly increased for both systems with increasing temperature. The $\mathrm{IFT}_{\text {equ }}$ at $80^{\circ} \mathrm{C}$ and $90{ }^{\circ} \mathrm{C}$ were above $0.01 \mathrm{mN} \mathrm{m}^{-1}$ (Fig. 3 and ESI Fig. $2 \dagger$ ). Probably because the hydrophobic interactions among surfactant molecules became weaker with the temperature increase, ${ }^{21}$ making the array of the interfacial surfactant molecule looser. ${ }^{\mathbf{1 8 2 2}}$ Moreover, when the temperature of the system increased and the molecular motion speeds up accordingly, the solvent molecules in the interface layer may be increased. ${ }^{21}$ The viscosity of the binary system was $32.8 \mathrm{mPa}$ s at $70{ }^{\circ} \mathrm{C}$ (ESI Table $6 \dagger)$.

The effects of $\mathrm{NaCl}$ and $\mathrm{Ca}^{2+}$ concentration $\left(\mathrm{CaCl}_{2}\right.$ was added in the solution) on IFT were showed in Fig. 4 and 5 (ESI Fig. 3 and $4 \dagger)$. Ultralow IFT $_{\text {equ }}$ was achieved when the concentration of $\mathrm{NaCl}$ below $15.00 \mathrm{~g} \mathrm{~L}^{-1}$ and the concentration of $\mathrm{Ca}^{2+}$ below $400 \mathrm{mg} \mathrm{L}^{-1}$. The excessive electrolyte ions destroy the hydration film around the hydrophilic head, promoting the surfactants on the oil/water interface to transfer to the oil phase and the interface tension increases with a reduction of aggregation degree. ${ }^{15,23}$ The salinities of most oil fields are normally below

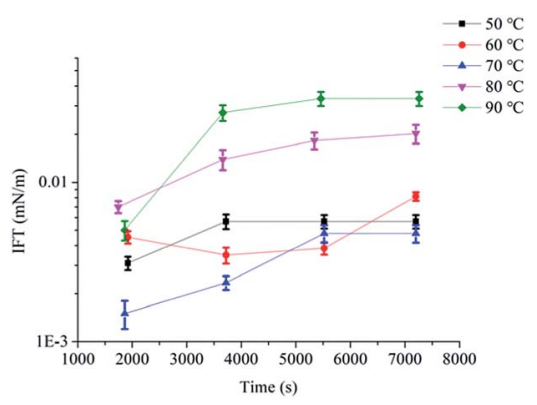

Fig. 3 Effects of temperatures on the IFTs between crude oil and POAPMB/AP-P3 system $(n=3)$.
$16.00 \mathrm{~g} \mathrm{~L} \mathrm{~L}^{-1}$ and the concentrations of $\mathrm{Ca}^{2+}$ are below $300 \mathrm{mg} \mathrm{L^{-114,24 }}$ in Chinese oilfields. The present results suggested that POAPMB/AP-P3 system had strong electrolyte tolerance, and it could remain good interfacial properties in a wide range of salinity. The viscosity retention rates of POAPMB/AP-P3 system were $55 \%$ and $77 \%$ at the conditions of $12.50 \mathrm{~g} \mathrm{~L}^{-1} \mathrm{NaCl}$ and $200 \mathrm{mg} \mathrm{L}^{-1} \mathrm{Ca}^{2+}$, respectively (ESI Table 7 and $8 \dagger$ ), which implied a possibility for its application in most oil fields in China.

Table 4 showed the viscosity of AP-P3 simulated formation water solution and POAPMB/AP-P3 system with aging time. The initial viscosity retention rate of POAPMB/AP-P3 system was $80 \%$. Guo et $a l .{ }^{5}$ reported that the initial viscosity retention rate of fatty acid disulfonate with hydrophobically associating polyacrylamide was $67 \%$ (ESI Table $11 \dagger$ ). The addition of POAPMB lowered the viscosity of polymer. Biggs et al. found that with the concentration of sodium dodecyl sulfate increased the viscosity of hydrophobically modified polyacrylamide solution rose first and felled later and accordingly proposed a threestage model..$^{25}$ The same phenomenon was observed in cation surfactant, $^{26}$ zwitterionic surfactant ${ }^{27}$ and nonionic ${ }^{28-30}$

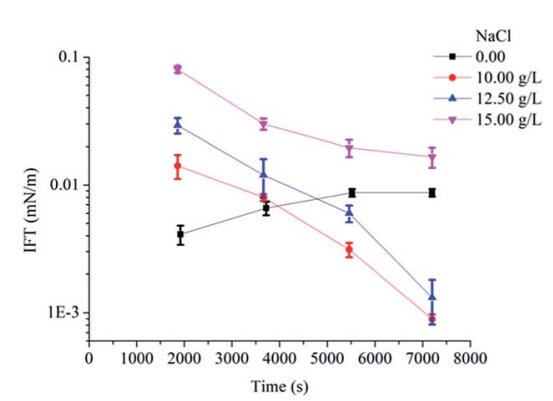

Fig. 4 Effects of concentrations of $\mathrm{NaCl}$ on the IFTs between crude oil and POAPMB/AP-P3 system $(n=3)$. 


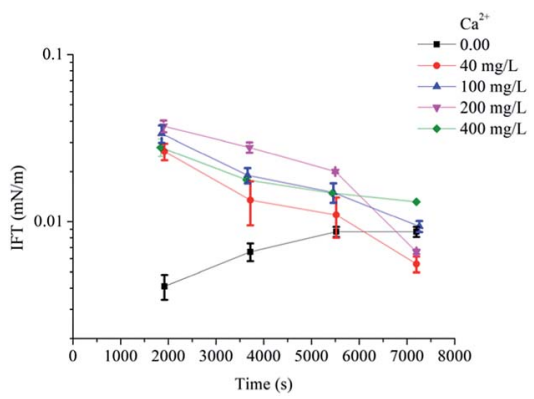

Fig. 5 Effects of concentrations of $\mathrm{Ca}^{2+}$ on the IFTs between crude oil and POAPMB/AP-P3 system $(n=3)$.

surfactants and hydrophobically associating polymer systems. The surfactant may incorporate to the polymer molecules in the form of spherical micelles. ${ }^{31}$ When the concentration of surfactant was high, hydrophobic region of hydrophobically associating polymer became solubilized by a single micelle. As a result, intermolecular association effects weakened and polymer network was destroyed (Region III), ${ }^{25}$ and the viscosity decreased. The viscosity of both solutions decreased over time. The viscosity retention rate after 30 days was $72 \%$ for POAPMB/ AP-P3 system, which implied a good viscosity stability.

Microemulsions are thermodynamically stable, macroscopically homogeneous mixtures of water, oil and one or more amphiphilic compounds. Microscopically, the surfactant molecules may form a film separating the two incompatible solvents into two domains. ${ }^{32}$ An $\mathrm{O} / \mathrm{W}$ middle phase microemulsion can been observed in the tube. "Solubilization ratio for oil (water) is defined as the ratio of the solubilized oil (water) volume to the surfactant volume in the microemulsion phase". ${ }^{33}$ Solubilization ratio for oil need to be higher than 10 as an effective surfactant flooding. ${ }^{33}$ According to observation and calculation, the solubilization ratio for oil was 40 for POAPMB/ AP-P3 system (Fig. 6). The particle size measurement (ESI Table $9 \dagger)$ showed that the polymer aggregates were formed in the bottom phase, and the surfactant molecules stayed in the middle phase as reported. ${ }^{33}$ The zeta potential of middle phase microemulsion was $-50.4 \mathrm{mV}$ (ESI Table $10 \dagger$ ), which implied the surfactant molecules formed an electrical double layer at the oil-aqueous interface. ${ }^{34}$ In general, values greater than $\pm 30 \mathrm{mV}$ suggested a good stability of the emulsions. ${ }^{34,35} \mathrm{In}$

Table 4 The viscosities of the polymer solution with aging time and POAPMB/AP-P3 system with aging time $\left(45^{\circ} \mathrm{C}, n=3\right)$

\begin{tabular}{lll}
\hline & $1.5 \mathrm{~g}$ & $\begin{array}{l}0.5 \mathrm{~g} \mathrm{~L} \mathrm{~L}^{-1} \text { POAPMB }+1.5 \mathrm{~g} \mathrm{~L}^{-1} \\
\text { Days-P3 viscosity }(\mathrm{mPa} \mathrm{s})\end{array}$ \\
\hline 0 & $\mathrm{~L}^{-1} \mathrm{AP}-\mathrm{P} 3$ viscosity (mPa s) & \\
2 & $58.4 \pm 0.5$ & $46.8 \pm 0.4$ \\
4 & $52.6 \pm 0.4$ & $44.9 \pm 0.3$ \\
7 & $51.6 \pm 0.5$ & $40.9 \pm 0.3$ \\
10 & $50.6 \pm 0.4$ & $42.0 \pm 0.4$ \\
15 & $50.2 \pm 0.4$ & $38.2 \pm 0.2$ \\
30 & $43.0 \pm 0.3$ & $37.1 \pm 0.3$ \\
60 & $35.1 \pm 0.3$ & $33.8 \pm 0.2$ \\
100 & $32.7 \pm 0.2$ & $26.2 \pm 0.2$ \\
& & $22.4 \pm 0.1$
\end{tabular}

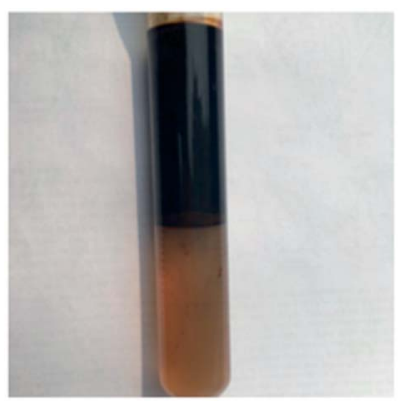

Fig. 6 Photograph of crude-oil-in-simulated formation water middle phase microemulsion taken after 3 weeks of settling $45^{\circ} \mathrm{C}$.

addition, emulsification of the crude oil to form the $\mathrm{O} / \mathrm{W}$ emulsion is beneficial for high recovery. ${ }^{2}$

\section{Conclusions}

The ultralow interfacial tension can be achieved in a low dosage of the biobased zwitterionic surfactant in the binary surfactantpolymer flooding system. The binary system exhibited a good anti-dilution and adsorption resistance, and it can keep ultralow IFT $_{\text {equ }}$ after 60 days; meanwhile, it showed an excellent salt resistance and good temperature adaptability. When mixed with crude oil, the $\mathrm{O} / \mathrm{W}$ middle phase microemulsion was formed and effective solubilization of crude oil was achieved, which implies that the binary flooding system is a kind of novel and cost-effective alkali free surfactant-polymer flooding system and is potential application in EOR.

\section{Conflicts of interest}

There are no conflicts of interest to declare.

\section{Acknowledgements}

This research was supported by the National Key Research and Development Program of China (No. 2017YFB0308900), and National Natural Science Foundation of China (No. 51574125).

\section{Notes and references}

1 G. J. Hirasaki, C. A. Miller and M. Puerto, SPE J., 2011, 16, 889-907.

2 L. M. Yan, Y. L. Li, Z. G. Cui, B. L. Song, X. M. Pei and J. Z. Jiang, Energy Fuels, 2017, 31, 9319-9327.

3 H. Clara, L. J. Chacon, A. Lorenzo, B. Abel, Q. Jie, C. Phillip and M. J. Pitts, SPE Reservoir Eval. Eng., 2003, 6, 147-156.

4 K. Zhang and J. S. Qin, Pet. Sci. Technol., 2011, 29, 183-191.

5 Y. J. Guo, J. X. Liu, X. M. Zhang, R. S. Feng, H. B. Li, J. Zhang, X. Lv and P. Y. Luo, Energy Fuels, 2012, 26, 2116-2123.

6 W. X. Situ, H. M. Lu, C. Y. Ruan, L. Zhang, Y. Zhu and L. Zhang, Colloids Surf., A, 2017, 533, 231-240.

7 P. Q. Gao, B. F. Towler, Y. Li and X. F. Zhang, SPE EOR Conference at Oil \& Gas West Asia, Muscat, Oman, 2010. 
8 Y. Zhu, G. Jian, W. Liu, L. Cheng, Q. Hou and J. Li, SPE Enhanced Oil Recovery Conference, Kuala Lumpur, Malaysia, 2013.

9 Z. G. Cui, D. Qi, B. L. Song, X. M. Pei and X. Hu, Energy Fuels, 2016, 30, 2043-2051.

10 L. M. Yan, Z. G. Cui, B. L. Song, X. M. Pei and J. Z. Jiang, Energy Fuels, 2017, 31, 3821-3829.

11 A. Bera, S. Kissmathulla, K. Ojha, T. Kumar and A. Mandal, Energy Fuels, 2012, 26, 3634-3643.

12 A. Kumar and A. Mandal, Colloids Surf., A, 2018, 549, 1-12.

13 N. Li, G. Zhang, J. Ge, J. Luchao, Z. Jianqiang, D. Baodong and H. Pei, Energy Fuels, 2011, 25, 4430-4437.

14 Q. Q. Zhang, B. X. Cai, H. Z. Gang, S. Z. Yang and B. Z. Mu, RSC Adv., 2014, 4, 38393-38399.

15 T. H. Zhao, J. Y. Gu, W. F. Pu, Z. M. Dong and R. Liu, RSC Adv., 2016, 6, 70165-70173.

16 C. Zhao, Y. Jiang, M. Li, T. Cheng, W. Yang and G. Zhou, RSC $A d v .$, 2018, 8, 6169-6177.

17 J. Zhao, C. Dai, Q. Ding, M. Du, H. Feng, Z. Wei, A. Chen and M. Zhao, RSC Adv., 2015, 5, 13993-14001.

18 S. Paria and K. C. Khilar, Adv. Colloid Interface Sci., 2004, 110, 75-95.

19 R. Zhang and P. Somasundaran, Adv. Colloid Interface Sci., 2006, 123-126, 213-229.

20 Z. G. Cui, W. Li, J. J. Qi and H. J. Wang, Colloids Surf., A, 2012, 414, 180-189.

21 Y. Cao, R. H. Zhao, L. Zhang, Z. C. Xu, Z. Q. Jin, L. Luo, L. Zhang and S. Zhao, Energy Fuels, 2012, 26, 2175-2181.
22 H. Zhou, H. Wu, Y. Yang, X. Leng, Y. Liang, P. Lian, Y. Song, Z. Yi, J. Liu and H. Jia, RSC Adv., 2017, 7, 32413-32418.

23 A. Bera, A. Mandal and B. Guha, J. Chem. Eng. Data, 2013, 59, 89-96.

24 L. Y. Wang, R. Y. Duan, J. F. Liu, S. Z. Yang, J. D. Gu and B. Z. Mu, Biogeosciences, 2012, 9, 4645-4659.

25 S. Biggs, J. Selb and F. Candau, Langmuir, 1992, 8, 838-847.

26 R. E. Jimenez, J. Selb and F. Candau, Langmuir, 2000, 16, 8611-8621.

27 S. Feng, H. Chen, Z. Hong, L. Xiao and J. Xian, Appl. Chem. Ind., 2015, 44, 87-91.

28 S. Talwar, J. Harding, K. R. Oleson and S. A. Khan, Langmuir, 2009, 25, 794-802.

29 S. Talwar, L. Scanu, S. R. Raghavan and S. A. Khan, Langmuir, 2008, 24, 7797-7802.

30 R. Liu, W. Pu, L. Wang, Q. Chen, Z. Li, Y. Li and B. Li, RSC Adv., 2015, 5, 69980-69989.

31 R. D. W. And, T. Cosgrove and L. Thompson, Langmuir, 2012, 15, 8376-8382.

32 S. Nave, F. Testard, H. Coulombeau, K. Baczko, C. Larpent and T. Zemb, Phys. Chem. Chem. Phys., 2009, 11, 2700-2707.

33 J. J. Sheng, Modern Chemical Enhanced Oil Recovery Theory and Practice, Elsevier, USA, 2011.

34 N. Kumar and A. Mandal, Energy Fuels, 2018, DOI: 10.1021/ acs.energyfuels.8b00043.

35 A. Bera, S. Kumar and A. Mandal, J. Chem. Eng. Data, 2012, 57, 3617-3623. 